\title{
STABILITY ANALYSIS OF SEED YIELD OF ADVANCED CHICKPEA (CICER ARIETINUM L.) GENOTYPES UNDER TROPICAL AND SUBTROPICAL RAINFED REGIONS OF IRAN
}

\author{
HAJIVAND, A. ${ }^{1}-$ ASGHARI, A. ${ }^{*}-$ KARIMIZADEH, R. ${ }^{2}-$ \\ MOHAMMADDOUST-CHAMANABAD, H. R. ${ }^{1}$ - ZEINALZADEH-TABRIZI, H. ${ }^{3}$ \\ ${ }^{l}$ Department of Agronomy and Plant Breeding, Faculty of Agriculture and Natural Resources, \\ University of Mohaghegh Ardabili, Ardabil, Iran \\ (phone: +98-914-304-2117; fax: +98-453-351-3920) \\ ${ }^{2}$ Dryland Agricultural Research Institute, Agricultural Research, Education and Extension \\ Organization (AREEO), Gachsaran, Iran \\ (phone: +98-917-344-5107; fax: +98-743-234-3402) \\ ${ }^{3}$ Crops and Horticultural Science Research Department, Ardabil Agricultural and Natural \\ Resources Research and Education Center (AREEO), Ardabil (Moghan), Iran \\ (phone: +98-453-275-1013; fax: +98-453-275-1420) \\ "Corresponding author \\ e-mail: a_asghari@uma.ac.ir; phone: +98-914-304-2117; fax: +98-453-351-3920
}

(Received $1^{\text {st }}$ Aug 2019; accepted $25^{\text {th }}$ Nov 2019)

\begin{abstract}
Evaluation of compatibility and stability of cultivars under different environmental conditions is a particular interest in crop breeding programs. In order to evaluate the seed yield stability of advanced chickpea genotypes under tropical and subtropical rainfed areas of Iran, 18 advanced chickpea genotypes and two check varieties (Adel and Azad) were studied in terms of randomized complete block design (RCBD) with three replications in four locations including Gachsaran, Gonbad, Khorramabad and Ilam using GGE biplot analysis during three growing seasons (2014-2017). Results of GGE biplot analysis and which-won-where pattern revealed that the genotype G13 was the most stable genotype for Khorramabad, Gachsaran and Gonbad while it was genotype G12 for Ilam. According to average tester coordinate (ATC), the genotype G13 was the most stable one across average test environment. The genotype G13 was also determined as a stable and high yielding genotype among all investigated genotypes and environments. Based on the average yield and Shukla Stability Index, as well as the mean of yield to maximum or Superiority Index (SI), G12, G13 genotypes were superior to the other genotypes in all regions with warm climate and thus be recommended.
\end{abstract}

Keywords: adaptation, environment, GGE biplot, interaction, promising line, superiority index

\section{Introduction}

The chickpea (Cicer arietinum L.) is a self-pollinated, diploid, and annual plant $(2 x=2 n=16)$. After peas and beans, it is the most important legume in the world (Varshney et al., 2013). The main countries producing chickpeas in the world are India, Pakistan, Turkey, Iran and Australia, respectively (Gan et al., 2005). The area under cultivation of chickpea in Iran is 650 thousand hectares and its annual production is about 350 thousand tons (Kanouni et al., 2016). Iran ranked seventh in the world for chickpea production after India, Australia, Turkey, Myanmar, Pakistan and Ethiopia (FAO, 2012). Farmers who grow chickpea need cultivars with high yields and maintain desirable qualities in a wide range of environmental conditions throughout the years (Zali et al., 2007; Tabrizi, 2012). The genotype by environment interaction (GEI) is the reaction of a variety to the changes in the environments (Yan et al., 2000). This interaction is 
important to plant breeding researchers and is one of the complexities of breeding programs for the preparation of a high-yielding and sustainable genotype (Yan et al., 2010; Karimizadeh et al., 2016). The GEI indicates a different sensitivity to environmental conditions, which means that the best genotype in an environment is not necessarily the best genotype in another environment (Farshadfar, 1998). Stability analysis is the most important method used to find out the nature of the GEI. Therefore, stable and compatible cultivars can be identified by using this analysis. Different methods have been proposed to investigate the GEI and the determination of stable genotypes, which include univariate and multivariate parametric and nonparametric methods (Dehghanpour et al., 2007; Mohammadi et al., 2012). The GGE biplot method is one of the multivariate methods for evaluating and interpreting the pattern response of cultivars, environments and their interaction (Gabriel, 1971). In the GGE biplot method, the effect of the genotype and the $\mathrm{G} \times \mathrm{E}$ are not separated and selection of cultivars with yield stability is based on both effects (Yan et al., 2000). What is important in assessing genotypes in different environments is that the environmental effect is very large in most cases, but not exploitable, thus eliminating the environmental impact of the data and focusing on the effects of genotype $(\mathrm{G})$ and the $\mathrm{G} \times \mathrm{E}$ are important (Yan and Kang, 2002). Only effect of the genotype and the $\mathrm{G} \times \mathrm{E}$ are important to select the lines with stable yield. The main point is that the two mentioned effects should be considered together (Yan, 2001). The GGE biplot method examines these two effects graphically (Yan, 2001). This method has been identified to be useful and applicable by numerous researchers for different crops for analyzing regional test data. Employing the GGE biplot method for selecting suitable chickpea cultivars (Kanouni et al., 2007; Zali et al., 2007; Farshadfar et al., 2012, 2013; Mostafavi et al., 2013; Pourdad and JamshidiMoghaddam, 2013; Shiri and Bahrampour, 2015), canola (Zali et al., 2016; Jabbari et al., 2019; Kheybari et al., 2019), bread wheat (Omrani et al., 2017), lentil (Karimzadeh et al., 2013), durum wheat (Mohammadi et al., 2016; Karimzadeh et al., 2019) for Iranian germplasm has been reported.

The present study aimed to investigate the GEI using GGE biplot methodology in chickpea genotypes to obtain high yielding cultivars, which are adapted with climatic conditions in tropical and subtropical regions of Iran.

\section{Materials and Methods}

\section{Description of the trials}

The plant materials used in this study were 18 advanced chickpea lines with two local check varieties (Adel and Azad) grown for three years (2014-2017) at each of four different locations in Iran. Geographical characteristics and soil properties of the test environments are presented in Table 1. These plant materials used in national chickpea breeding program for rainfed areas of Iran are provided from the International Centre for Agricultural Research in the Dry Areas (ICARDA) chickpea international breeding program. Genotype names and their pedigrees are presented in Table 2.

Seed density for each genotype was 50 seed per $\mathrm{m}^{2}$ and planting was done using experimental planter's machine. Sowing date of all experiments was November 15. Each plot consists of five plant rows, $6 \mathrm{~m}$ length with row space of $25 \mathrm{~cm}$. Therefore, the size of each plot was $7 \mathrm{~m}^{2}$. Fertilizers were applied $100 \mathrm{~kg} \mathrm{ha}^{-1}$ of ammonium phosphate as triple super phosphate at planting time, and $35 \mathrm{~kg}$ of urea during field preparation. No disease was shown during growth period. Weed control and thinning of plants were done 
by hand during the experiments. To avoid the marginal effects, $25 \mathrm{~cm}$ from the beginning and end of the rows of each experimental plot was removed. Then $5 \mathrm{~m}^{2}$ of each plot were harvested at physiological maturity of each genotype and finally seed yield of each plot was weighted. Weather data of the test site locations during the experiments are presented in Table 3.

Table 1. Geographical characteristics and soil properties of the test environments

\begin{tabular}{|c|c|c|c|c|c|}
\hline $\begin{array}{c}\text { Test environment } \\
\text { name }\end{array}$ & $\begin{array}{c}\text { Longitude } \\
\text { and Latitude }\end{array}$ & $\begin{array}{c}\text { Altitude } \\
\text { (m) }\end{array}$ & Soil Texture & Soil Type & $\begin{array}{c}\text { Annual } \\
\text { Precipitation } \\
(\mathbf{m m})\end{array}$ \\
\hline Gachsaran & $\begin{array}{l}3021 \mathrm{~N} \\
5047 \mathrm{E}\end{array}$ & 726 & Silty Clay Loam & Regosols & 455 \\
\hline Gonbad & $\begin{array}{l}5518 \mathrm{~N} \\
3717 \mathrm{E}\end{array}$ & 45 & Silty Clay Loam & Regosols & 367 \\
\hline Ilam & $\begin{array}{l}3336 \mathrm{~N} \\
4636 \mathrm{E}\end{array}$ & 1427 & Clay Loam & Regosols & 502 \\
\hline Khorramabad & $\begin{array}{l}3348 \mathrm{~N} \\
4835 \mathrm{E}\end{array}$ & 1148 & Silt-Loam & Regosols & 433 \\
\hline
\end{tabular}

Table 2. The name, origin and code of the studied chickpea genotypes

\begin{tabular}{l|c|c}
\hline \multicolumn{1}{c|}{ Name/Pedigree } & Origin & Code \\
\hline FLIP03-26C/3/98TH70/4/(FLIP93-210C/ FLIP87-8C)//S96086 & ICARDA & G1 \\
FLIP06-17C//2002TH 18/3/FLIP98-130C / FLIP98-120C & ICARDA & G2 \\
FLIP06-39C//2002TH 37/3/S99520 / FLIP98-048C & ICARDA & G3 \\
FLIP06-43C//2002TH 40/3/FLIP98-28C/ FLIP98-079C & ICARDA & G4 \\
FLIP06-97C/4/2002TH 119/5/[(FLIP 98-64C/ FLIP98-47C)//Se199ter85488]/3/ & ICARDA & G5 \\
FLIP98-022C & ICARDA & G6 \\
FLIP06-120C/3/2002TH 131/4/(ILWC 141/S85581)//FLIP98-130C & ICARDA & G7 \\
FLIP07-201C/3/03TH-20/4/(S00784/FLIP97-28C)//ICCV2 & ICARDA & G8 \\
FLIP88-85C//85 TH143/3/ILC 629 / FLIP 82-144C & ICARDA & G9 \\
FLIP06-59C//2002TH 76/3/S99858/FLIP 97-026C & ICARDA & G10 \\
FLIP03-141C/3/00TH 51//FLIP98-52C/FLIP98-47C & ICARDA & G11 \\
FLIP05-44C/3/2000TH 39//FLIP98-29C/S99001 & ICARDA & G12 \\
FLIP05-46C/3/2000TH 39//FLIP98-29C/S99001 & ICARDA & G13 \\
FLIP05-46C/3/2000TH 39/FLIP98-29C//S99001 & ICARDA & G14 \\
FLIP07-11C/3/03TH-138/FLIP98-130C//FLIP99-34C. & ICARDA & G15 \\
FLIP07-33C/3/03TH-153/FLIP98-133C//FLIP98-117C & ICARDA & G16 \\
FLIP08-14C/4/00TH95//(FLIP84-182C/FLIP91-138C)/3/ S99075 & ICARDA & G17 \\
FLIP08-58C/3/02TH3/FLIP 98- 28C // FLIP 97-102C & ICARDA & G18 \\
FLIP03-31C/3/98TH18//S96114/FLIP 92-148C & IRAN & G19 \\
ADEL (99-66C) (check) & IRAN & G20 \\
AZAD (check) & &
\end{tabular}


Table 3. Weather data of the test site locations

\begin{tabular}{|c|c|c|c|c|c|c|c|c|c|c|c|c|c|c|c|c|c|}
\hline & & \multicolumn{5}{|c|}{ OCT } & \multicolumn{3}{|c|}{ NOV } & \multicolumn{4}{|c|}{ DEC } & \multicolumn{4}{|c|}{ JAN } \\
\hline & & 2014 & \multicolumn{2}{|c|}{2015} & \multicolumn{2}{|c|}{2016} & 2014 & 2015 & 2016 & \multicolumn{2}{|c|}{2014} & 2015 & 2016 & 2015 & \multicolumn{2}{|c|}{2016} & 2017 \\
\hline \multirow{4}{*}{ Precipitation $(\mathrm{mm})$} & Gachsaran & 7.4 & \multicolumn{2}{|c|}{0.0} & \multicolumn{2}{|c|}{0.0} & 31.1 & 81.7 & 3.4 & \multicolumn{2}{|c|}{107.9} & 57.5 & 78.6 & 5.5 & \multicolumn{2}{|c|}{139.4} & 4.0 \\
\hline & Gonbad & 24.3 & \multicolumn{2}{|c|}{37.9} & \multicolumn{2}{|c|}{29.8} & 41.6 & 99.6 & 58.2 & \multicolumn{2}{|c|}{48.5} & 61.0 & 37.5 & 14.0 & \multicolumn{2}{|c|}{43.1} & 9.0 \\
\hline & Ilam & 50.7 & \multicolumn{2}{|c|}{0.5} & \multicolumn{2}{|c|}{2.7} & 77.7 & 319.6 & 1.9 & \multicolumn{2}{|c|}{45.1} & 67.7 & 35.3 & 17.2 & \multicolumn{2}{|c|}{75.9} & 87.5 \\
\hline & Khorramabad & 70.3 & \multicolumn{2}{|c|}{14.0} & \multicolumn{2}{|c|}{0.0} & 33.9 & 190.8 & 8.6 & \multicolumn{2}{|c|}{61.6} & 125.4 & 66.2 & 9.6 & \multicolumn{2}{|c|}{57.5} & 82.6 \\
\hline \multirow{4}{*}{$\begin{array}{c}\text { Average } \\
\text { temperature }\left({ }^{\circ} \mathrm{C}\right)\end{array}$} & Gachsaran & 25.5 & \multicolumn{2}{|c|}{27.3} & \multicolumn{2}{|c|}{24.8} & 17.5 & 18.3 & 20.4 & \multicolumn{2}{|c|}{17.8} & 13.2 & 14.1 & 11.9 & \multicolumn{2}{|c|}{11.2} & 14.5 \\
\hline & Gonbad & 21.4 & & & & 1.4 & 14.4 & 17.5 & 14.7 & & & 12.7 & 8.3 & 10.2 & & 3.0 & 10.7 \\
\hline & Ilam & 20.1 & 24 & & & 2.0 & 13.3 & 13.9 & 17.3 & & & 8.1 & 8.1 & 6.7 & & .7 & 7.3 \\
\hline & Khorramabad & 19.9 & 21 & & & .7 & 11.5 & 13.2 & 15.5 & & & 6.7 & 7.2 & 6.0 & & .2 & 6.9 \\
\hline & & & FEB & & & & MAR & & & APR & & & MAY & & & JUN & \\
\hline & & 2015 & 2016 & 20 & & 2015 & 2016 & 2017 & 2015 & 2016 & 2017 & 2015 & 2016 & 2017 & 2015 & 2016 & 2017 \\
\hline & Gachsaran & 12.8 & 30.5 & 88 & & 83.3 & 21.7 & 25.3 & 63.8 & 57.3 & 28.7 & 3.8 & 2.0 & 8.4 & 0.0 & 0.0 & 0.0 \\
\hline & Gonbad & 40.9 & 49.4 & 94 & & 76.9 & 52.1 & 35.6 & 25.1 & 65.1 & 37.2 & 8.0 & 27.8 & 30.4 & 0.1 & 42.8 & 0.3 \\
\hline Precipitation (mm) & Ilam & 18.7 & 56.9 & 10 & & 59.2 & 53.0 & 74.7 & 58.9 & 138.6 & 93.8 & 7.5 & 25.6 & 10.7 & 0.1 & 0.0 & 0.0 \\
\hline & Khorramabad & 34.0 & 30.6 & 1( & & 52.9 & 63.9 & 44.3 & 51.4 & 244 & 80.8 & 12.6 & 17.2 & 32.8 & 0.0 & 0.0 & 0.0 \\
\hline & Gachsaran & 14.8 & 11.4 & 11 & & 14.2 & 16.1 & 14.9 & 19.6 & 17.3 & 20.0 & 26.2 & 25.9 & 26.6 & 32.1 & 33.2 & 30.8 \\
\hline Average & Gonbad & 10.2 & 12.9 & 9 & & 9.2 & 16.0 & 14.9 & 14.8 & 16.7 & 18.0 & 20.7 & 25.1 & 24.4 & 28.8 & 26.8 & 27.1 \\
\hline temperature $\left({ }^{\circ} \mathrm{C}\right)$ & Ilam & 9.3 & 7.0 & 4 & & 9.3 & 12.0 & 10.2 & 16.1 & 12.9 & 14.0 & 19.8 & 20.4 & 21.1 & 28.3 & 28.5 & 26.2 \\
\hline & Khorramabad & 9.3 & 6.2 & 4 & & 9.3 & 11.5 & 9.4 & 13.5 & 11.7 & 14.1 & 20.0 & 19.7 & 20.1 & 26.1 & 21.3 & 24.5 \\
\hline
\end{tabular}




\section{Statistical analysis}

The experimental design in all locations was a randomized complete block design with four replicates. Outliers were firstly detected using Grubb's test (Grubbs, 1969) before variance analysis. Then the normality of seed yield data was checked by the Shapiro-Wilk test (Shapiro and Wilk, 1965). To test the uniformity of the variance of experimental errors, the Levene test (Leven, 1960) and Bartlett's test (Bartlett, 1937) were employed. Combined analysis was performed by SAS 9.1 software package. Graphical stability analysis was performed using GGE biplot software version 6.3 (Yan, 2001).

Model 1 based on singular value decomposition (SVD) of tester-centered data of the first two principal components was chosen to construct various biplots. This model is used for dataset in which all testers have the same unit, such as a genotype-byenvironment table of a single trait like seed yield in this study.

The model is: Yij $-\mathrm{u}-\beta \mathrm{j}=$ gil e $1 \mathrm{j}+$ gi $2 \mathrm{e} 2 \mathrm{j}+\mathrm{\varepsilon ij}$; where: Yij is the performance expected seed yield of genotype (entry) $i$ in location (environment) $j ; \mu$ is the overall mean of the observations; $\beta \mathrm{j}$ is the main effect of location $\mathrm{j}$; $g 1 \mathrm{i}$ and $\mathrm{e} 1 \mathrm{j}$ are the primary scores for the ith genotype in the jth environment, respectively; gi2 and e $2 \mathrm{j}$ are the secondary scores for the ith genotype in the jth environment, respectively; and eij is the residual not explained by primary and secondary effects (Yan and Kang, 2002). Therefore, biplot in the GGE biplot model is generated by the simple dispersion of g1i and gi2 for genotypes and $\mathrm{e} 1 \mathrm{j}$ and $\mathrm{e} 2 \mathrm{j}$ for environments, via singular value decomposition, in accordance with the equation Yij $-\mu-\beta \mathrm{j}=\lambda 1 \xi \mathrm{i} 1 \eta 1 \mathrm{j}+\lambda 2 \xi \mathrm{i} 2 \eta 2 \mathrm{j}+\varepsilon \mathrm{ij}$, where $\lambda 1$ and $\lambda 2$ are the largest eigenvalues of the first and second principal components, PC1 and PC2, respectively; $\xi$ i1 and $\xi \mathrm{i} 2$ are the eigenvalues of the ith genotype for PC1 and PC2, respectively; and $\eta 1 \mathrm{j}$ and $\eta 2 \mathrm{j}$ are the eigenvalues of the jth environment for PC1 and PC2, respectively (Yan and Kang, 2002).

Superiority Index (SI) was calculated using YREM which refers to "Yield relative to the maximum". The output is the average YREM of each genotype across environments. It is a $[0,1]$ superiority index, the larger the value of a genotype the more superior it is (Yan, 1999).

\section{Results and Discussion}

Before combined analysis of data, the results of the Levene's Test $\left(1.35^{\text {ns }}\right)$ and Bartlett's test $\left(11.53^{\text {ns }}\right)$ to ensure the uniformity of the experimental errors in the test environments showed that there is a uniformity of error among the variances of the experimental errors. Therefore, combined analysis can be carried out. Combined analysis of variance showed that there was a significant difference between the genotypes in terms of seed yield at a probability level of 0.05 . The $\mathrm{G} \times \mathrm{E}$ was also significant (Table 4). The significance of the $\mathrm{G} \times \mathrm{Y} \times \mathrm{E}$ indicated that the mean seed yield of chickpea genotypes was different across different locations. Therefore, stability analysis could be used to identify genotypes or stable genotypes. This model is suitable for a series of data that have the same units as the genotype table in the environment for a trait, such as the seed yield in this study.

Graphical analysis of chickpea genotypes by GGE biplot method showed that the first two components explained $62.5 \%$ of variations in seed yield in different environments. $32.9 \%$ of these variations belonged to the first component, and $29.6 \%$ belonged to the second component. According to Yan and Kang (2002), if GGE biplot methodology can 
explain at least $60 \%$ of the variance of the total data, it can be applicable and useful for evaluating mega environments.

Table 4. Combined analysis of seed yield in chickpea genotypes across different environments

\begin{tabular}{c|c|c}
\hline S.O.V & Df & MS \\
\hline Year $(\mathrm{Y})$ & 2 & $4816696.8^{\mathrm{ns}}$ \\
Location $(\mathrm{P})$ & 3 & $68100256.5^{*}$ \\
$\mathrm{Y} \times \mathrm{P}$ & 6 & $13945279.2^{* *}$ \\
Error & 24 & 403237.2 \\
Genotypes $(\mathrm{G})$ & 19 & $251286.3^{*}$ \\
$\mathrm{G} \times \mathrm{Y}$ & 38 & $107198.9^{\mathrm{ns}}$ \\
$\mathrm{G} \times \mathrm{P}$ & 57 & $227210.2^{* *}$ \\
$\mathrm{G} \times \mathrm{Y} \times \mathrm{P}$ & 114 & $106548.1^{* *}$ \\
Error & 456 & 77917 \\
Total & 719 & \\
CV\% & 19.38 & \\
\hline
\end{tabular}

ns * and **: non-significant, significant at $5 \%$ and $1 \%$ probability level, respectively

Total variance percentages, as well as the percentage of the first and second components in Maqbool et al. (2015) study, were $98.61 \%, 87.67 \%$, and $10.49 \%$, respectively. In Kanouni et al. (2016), the values were, $66.43 \%, 43.09 \%$ and $23.34 \%$, and in Usefi et al. (2017) they were 75\%, 46\%, and 29\%, respectively. Table 5 illustrates the variance values explained by genotype, environment, and $\mathrm{G} \times \mathrm{E}$. Accordingly, $2.15 \%$ of the total variance, as explained by the first two components of the biplot analysis was related to the genotype $(\mathrm{G}), 92.02 \%$ was related to the environment (year and location), and $5.83 \%$ was related to the $\mathrm{G} \times \mathrm{E}$. In Farshadfar et al. (2011) conducted on the stability of chickpea cultivars, $2.48 \%$ of the total variance was related to the genotype, $86.44 \%$ was related to the effect of the environment, and $11.08 \%$ was related to the $\mathrm{G} \times \mathrm{E}$, which are with consistent with the results of the present research. Gauch and Zobel (1996) concluded that the large environment main effect, however, is not relevant to cultivar evaluation. Only $\mathrm{G}$ and $\mathrm{G} \times \mathrm{E}$ are relevant to cultivar evaluation. Therefore, for cultivar evaluation, it is essential to remove $\mathrm{E}$ from data and to focus on $\mathrm{G}$ and $\mathrm{G} \times \mathrm{E}$. Thus, large environment main effect reported in this study was in accordance with previous studies. Another important point in cultivar evaluation and stability analysis is that $G$ and $G \times E$ must be considered simultaneously to make any meaningful selection decisions (Yan and Kang, 2002).

Table 5. Relative magnitude of the genotype, environment and their interaction based on two first components of biplot analysis

\begin{tabular}{c|c|c}
\hline S.O.V & SS & Percentage of total variance \\
\hline Genotype (G) & 1591434 & 2.15 \\
Environment (E) & 68097475 & 92.02 \\
G×E & 4317009 & 5.83 \\
Total & 74005918 & \\
\hline
\end{tabular}


Assessment of test environments showed that the highest seed yield was obtained in Khorramabad, and the lowest was in Gachsaran. Also, Gonbad has highest, and Khorramabad the lowest coefficient of environmental variations among testers. In terms of heritability of the test environments, Gonbad and Gachsaran have the highest values, indicating the power of differentiation of these regions in the discriminating of genotypes in terms of stability (Table 6).

Table 6. Mean yield, heritability and coefficient of variations of the test environments

\begin{tabular}{c|c|c|c|c}
\hline Test environment name & $\begin{array}{c}\text { Mean Yield } \\
\left(\mathbf{k g ~ h a}^{-1}\right)\end{array}$ & $\begin{array}{c}\text { Standard } \\
\text { Error }\end{array}$ & Heritability & $\begin{array}{c}\mathbf{C V} \\
\mathbf{( \% )}\end{array}$ \\
\hline Gachsaran & 1029.065 & 115.891 & 0.668 & 11.26 \\
Gonbad & 1241.449 & 174.349 & 0.723 & 14.04 \\
Ilam & 1136.55 & 142.364 & 0.637 & 12.53 \\
Khorramabad & 2353.557 & 238.292 & 0.459 & 10.12 \\
\hline
\end{tabular}

The heritability values reflect the variation detected among the genotypes, which will be greater when increase the environment discriminating ability (Cravero et al., 2010).

Fig. 1 shows a biplot graphical analysis and a which-won-where pattern of 20 genotypes of chickpea based on the mean seed yield in four environments examined. The visualization of the which-won-where pattern is important in multi-environmental data to study the possibility of having large environments in a region. The biplot polygon diagram is the best way to visualize the patterns of $\mathrm{G} \times \mathrm{E}$ and to correctly interpret a biplot (Yan and Tinker, 2006). Accordingly, G13 was the most stable one in Khorramabad and Gachsaran, and G12 was the highest yielding and most stable one for Ilam (Fig. 1). This conclusion can also be obtained from drawing specific biplots for each location (Figs. 2, 3, 4, and 5). In other words, the G13 in Khorramabad, Gachsaran and Gonbad, and G12 in Ilam have a specific adaptability to the locations.

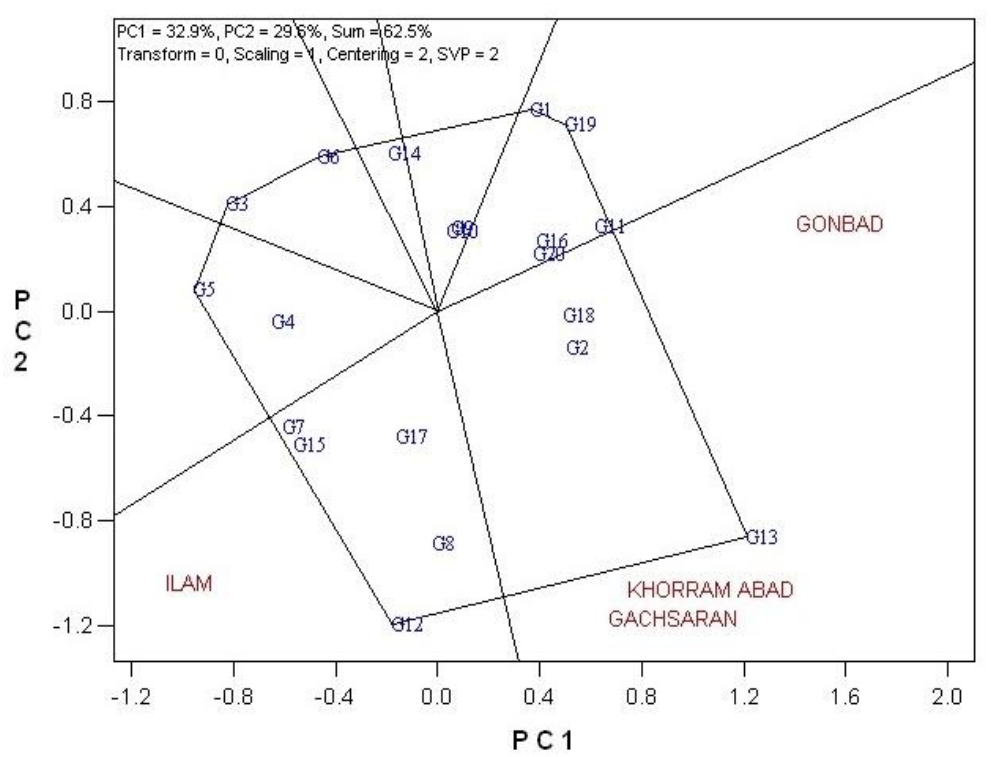

Figure 1. Which-won-where pattern biplot based on seed yield of chickpea genotypes in different test environments 


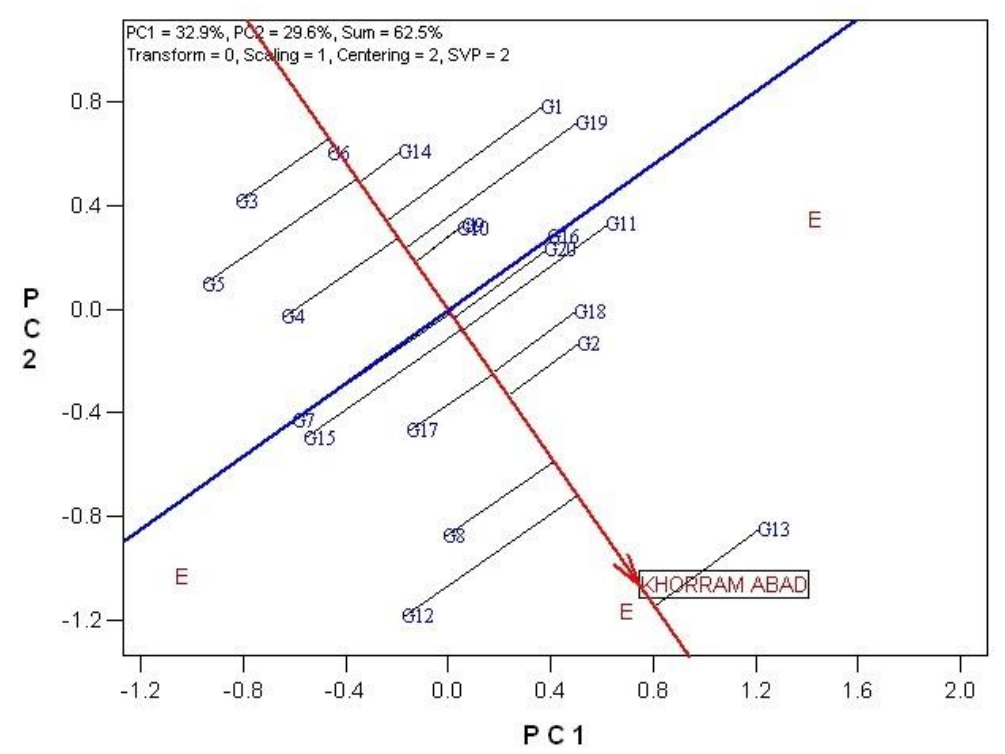

Figure 2. Ranking of all genotypes and determination of specific adaptability in the Khorramabad test environment

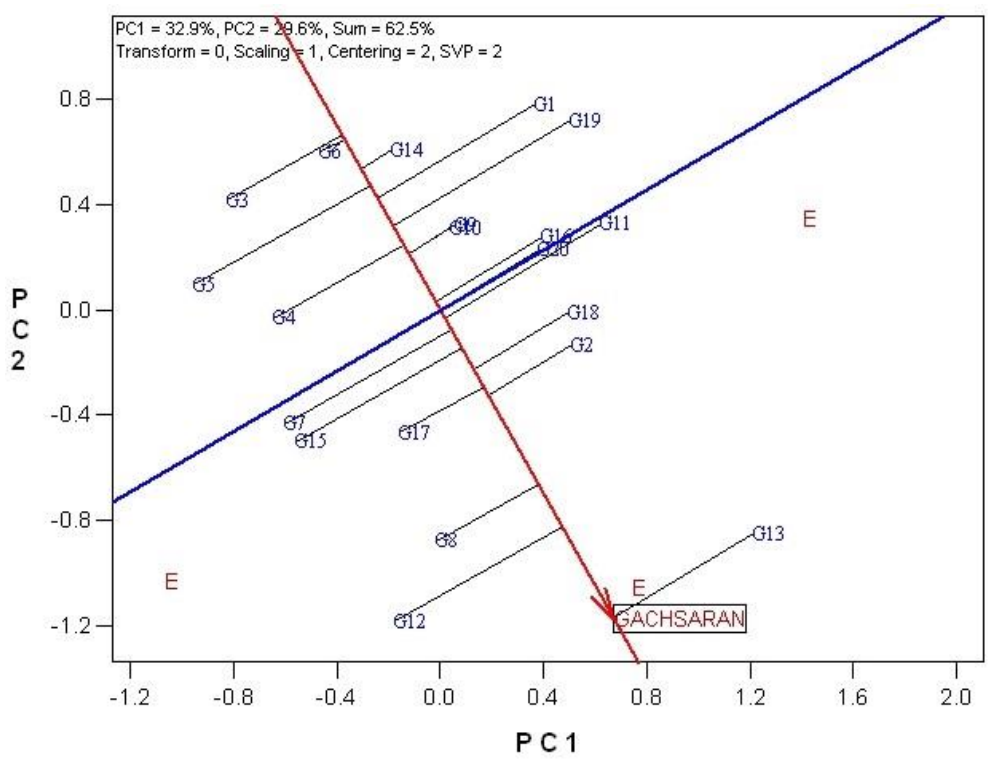

Figure 3. Ranking of all genotypes and determination of specific adaptability in the Gachsaran test environment

Also, genotype G5 at the left side of the biplot had the lowest seed yield and stability among the genotypes tested. In Figs. 2, 3, and 4, the red axis, indicates the mean yield of genotypes $(\mathrm{G})$ and the perpendicular blue axis indicates the $\mathrm{G} \times \mathrm{E}$. Thus, from the right side of the biplot to the left, the genotype yield decreases. The best genotype is a genotype that is inclined to the positive end of red axis and its vertical distance is shortest from this line. Genotypes with the shortest distance from the center have more stability (Yan and Kang, 2002). 


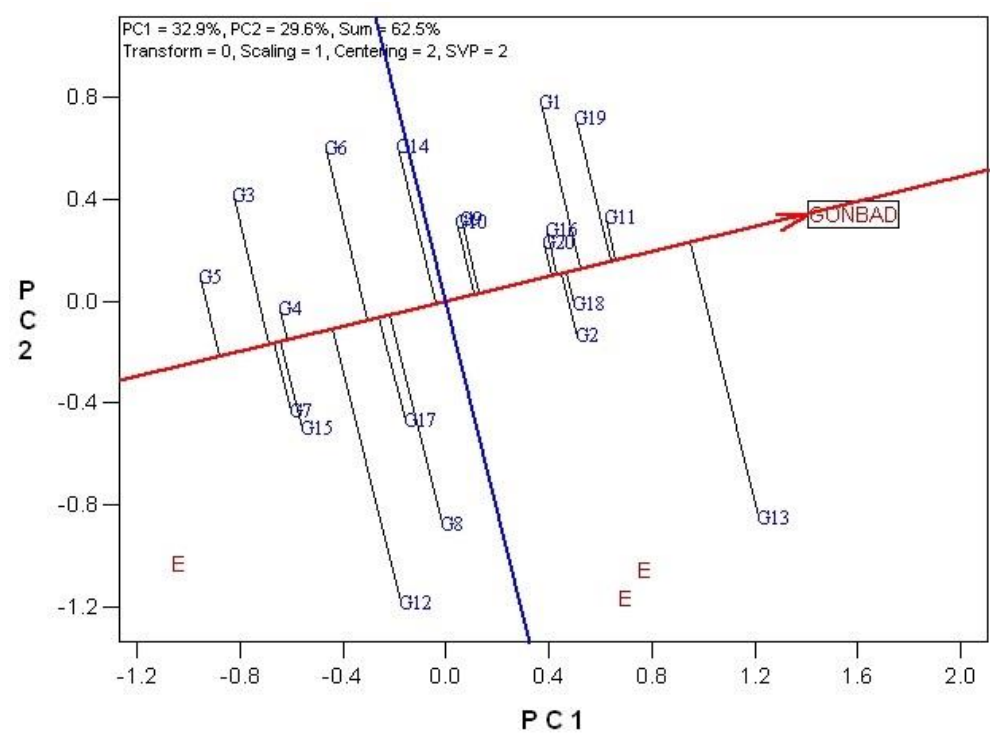

Figure 4. Ranking of all genotypes and determination of specific adaptability in the Gonbad test environment

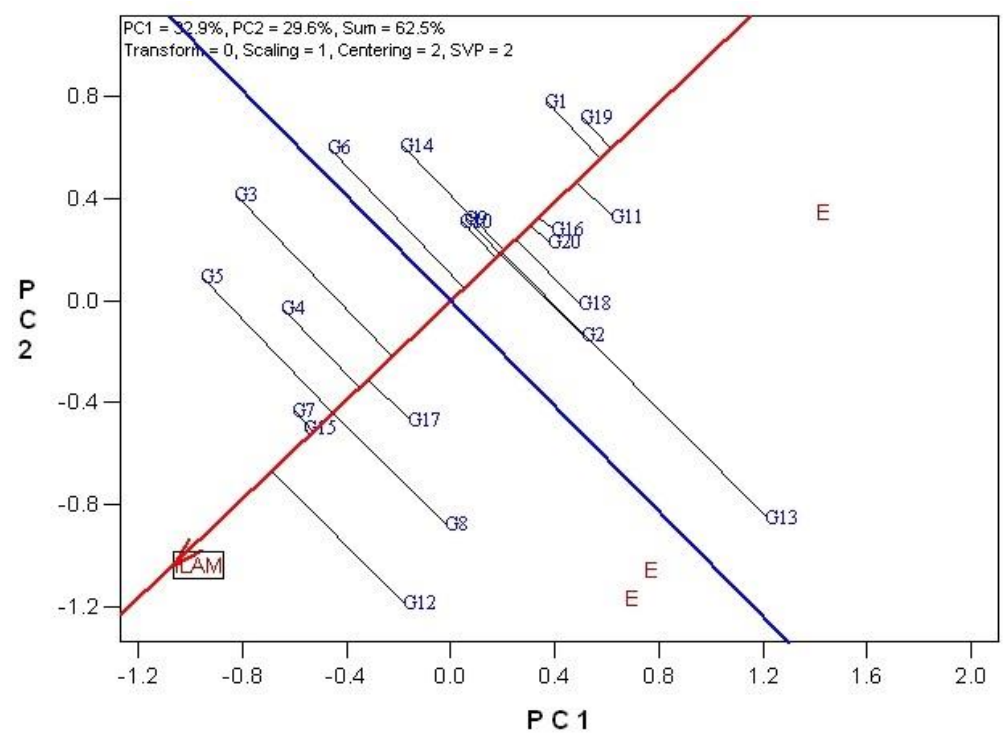

Figure 5. Ranking of all genotypes and determination of specific adaptability in the Ilam test environment

To examine the stability and yield of genotypes the Average Environment Coordination (AEC) was used (Fig. 6). In this biplot, the horizontal axis with an arrow moves from the origin of the coordinates (Yan et al., 2000). The images of genotypes on this axis represent approximately their yield. This axis is called the average environment axis. The results of the biplot (Fig. 6) showed that G13 was the most efficient and stable genotype in the average environment of all test environments. The vertical axis, originating from the coordinates of the past and perpendicular to the average environment axis indicates the $\mathrm{G} \times \mathrm{E}$ and determines the stability of the genotypes. How much vertical distance is highest from red line, represents unstable mean yield. One of the features of 
GGE biplot analysis is based on the analysis of the main components is genotype-based scaling, and using the same unit for both horizontal and vertical axes, which allows more accurate examination of genotypes. This feature can be used to show the average of genotype and stability simultaneously (Farshadfar et al., 2011). The common unit for the mean yield and stability allows both criteria of yield and stability can be combined and conceptualized into a single criterion. The display of average genotype and stability of genotypes can be possible through drawing an axis that passes through the biplot and the average environment (small red circle on the axis). The images of the signs of genotypes on this axis are estimations of their mean yield (Yan and Kang, 2002). The correlation coefficient between this ranking and the average genotype yield was 0.927 , indicating an appropriate explanation of the average genotypes on the average environment axis. Direction of red arrow displays a higher average. The blue vertical axis provides an estimate of the interaction and stability of the genotypes, and distance from the source (the intersection with the red axis) is a criterion for the variability or instability of genotypes. Moreover, the vertical blue axis, perpendicular to the red axis, provides an estimate of the interaction and stability of the genotypes, and the distance from the origin, (the intersection with the red axis) is a criterion for variability or instability of genotypes.

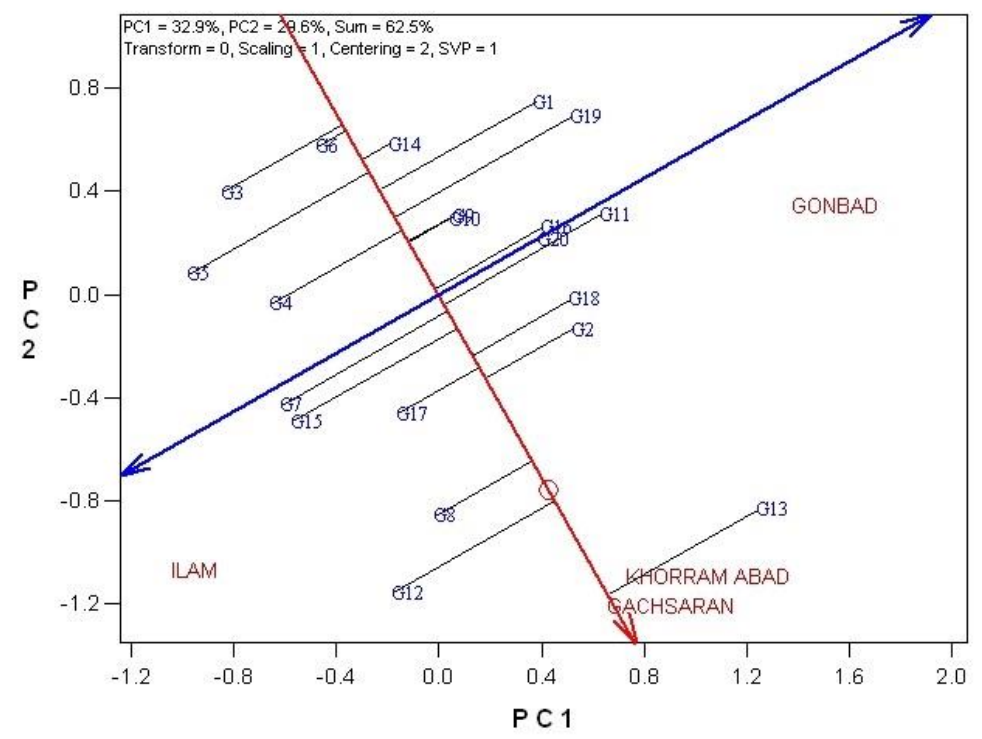

Figure 6. Average Environment Coordination (AEC) of seed yield stability in chickpea genotypes using GGE biplot analysis in different test environments

The stability criterion determined by the $\mathrm{G} \times \mathrm{E}$ is only useful when considered together with the mean yield (G) (Yan, 1999). For example, in Fig. 6 it seems that G4 is more stable than G13 because it is less close to the average environment vector, but is not desirable because it has a much lower yield than G13. Kang (1993) and Yan (1999) concluded that stability is a non-dimensional value which displays a high-yield value better, but displays a low-yield value worse. Eskridge (1996) concluded that stability is less inherited than mean yield. Therefore, stability, along with the mean yield, are useful, and the GGE biplot methodology converts it to a benchmark that can be evaluated graphically (Yan et al., 2000). 
Fig. 7 shows the biplot of comparison different test environments with the ideal test environment, and vector display of the interaction between them based on the seed yield of the chickpea genotypes using the graphical GGE biplot analysis. For this purpose, the origin of the linear coordinates is connected to the point of the average environments and continues to the sides. The best environment is the environment that is closer to the center of the circles. Since the comparison of genotypes in this biplot is not indicated, they are shown with small circles. Based on this biplot, Gachsaran and Khorramabad regions had higher representation and differentiation than Gonbad and Ilam in terms of differentiation and discriminating of the genotypes. In fact, the length of each test environment estimates the standard deviation within each environment. The longer the test environment, the more power of differentiation and representativeness of that environment (Yan and Kang, 2002).

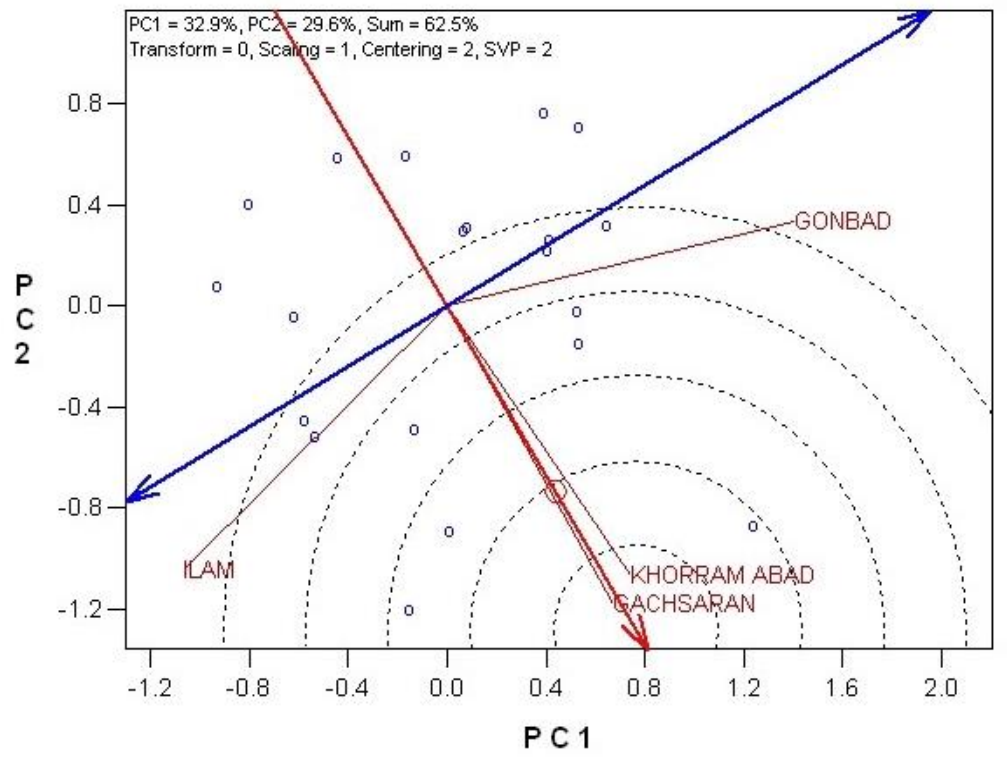

Figure 7. Biplot for comparison environments with the ideal environment and vector display of the interaction between them based on seed yield of chickpea genotypes

Table 7 shows the correlation coefficients between different environments. As Table 7 illustrates, there is no significant positive correlation between each environment, in other words the effect of the year was different during the three years of the experiment. The GGE biplot method is also used to separate of similar environments from non-similar (Navabi et al., 2006).

Table 7. Correlation coefficients among different test environments

\begin{tabular}{c|c|c|c|c}
\hline Location & Gachsaran & Gonbad & Ilam & Khorramabad \\
\hline Gachsaran & 1 & & & \\
Gonbad & 0.106 & 1 & & \\
Ilam & 0.064 & -0.281 & 1 & \\
Khorramabad & 0.176 & 0.100 & 0.023 & 1 \\
\hline
\end{tabular}


In fact, in the fitted model of GGE biplot, the cosine of the angle between any two environments approximates their correlation coefficient between them (Yan and Kang, 2002). In this study, Gachsaran and Khorramabad have a close angle between their vectors, therefore, they should be correlated. Indeed, the correlation coefficient between them is 0.176 because the model is not $100 \%$ fitted. Yan and Kang (2002) concluded that the cosine of the angles does not precisely translate into correlation coefficients, since the biplot does not explain all of the variation in a dataset.

Fig. 8 shows the biplot of comparison of all genotypes with the ideal genotype. The red circle on the red axis represents the ideal hypothetical genotype that has the highest yield and stability among all genotypes and environments. In practice, however, such a genotype does not exist, but the ranking of other genotypes is estimated based on this ideal genotype (Yan and Kang, 2002). Accordingly, G13 was identified as a stable and high yield genotype among all genotypes and environments (Fig. 8). The correlation coefficient was calculated between the average genotypes and their distance on the biplot as -0.903 , indicating a proper explanation of the biplot of comparison of the genotypes with the ideal genotype. Moreover, the results of this biplot were consistent with the results of the biplot of the average environment (Fig. 6).

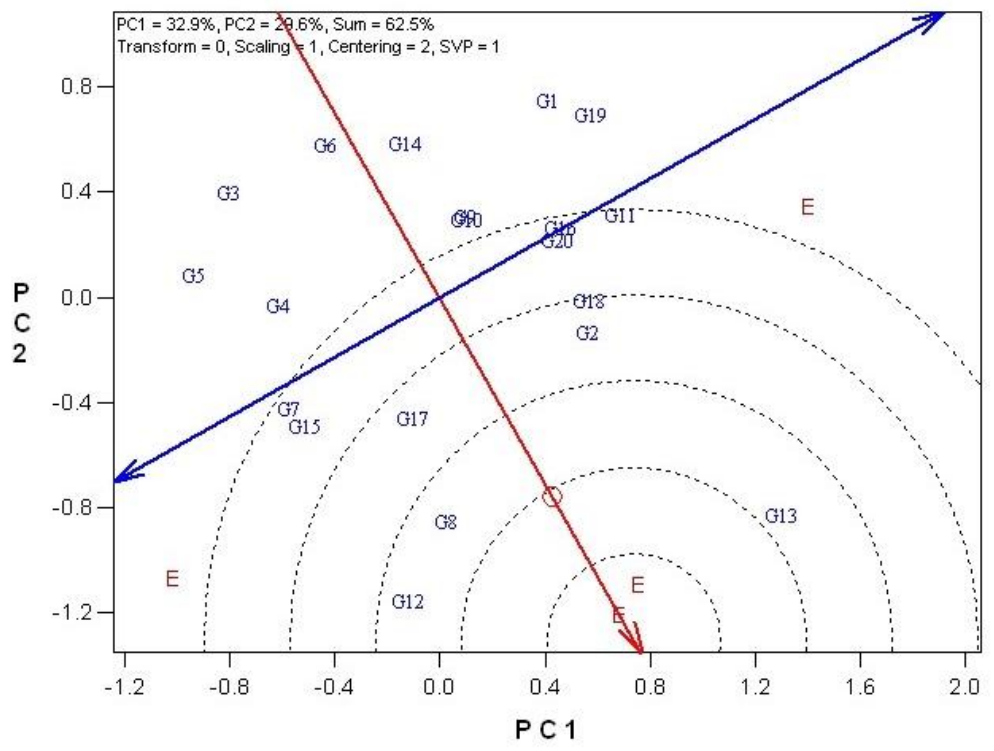

Figure 8. Biplot drawn based on genotype-focused scaling for comparison of chickpea genotypes with an ideal genotype

Fig. 9 shows the mean seed yield of chickpea genotypes versus the deviation of their stability (Shukla's Stability Index). Accordingly, genotypes G13 and G12 were superior to the other genotypes.

Fig. 10 displays the mean seed yield in relation with the maximum seed yield (YERM) or Superiority Index of seed yield of chickpea genotypes versus the deviation of the stability of the superiority index. Accordingly, genotypes G13 and G12 were superior to other genotypes in all regions of the study. This criterion, which was first suggested by Yan (1999), is a superiority index based on (0 and 1), so that the larger its value, the more stable its genotype. 


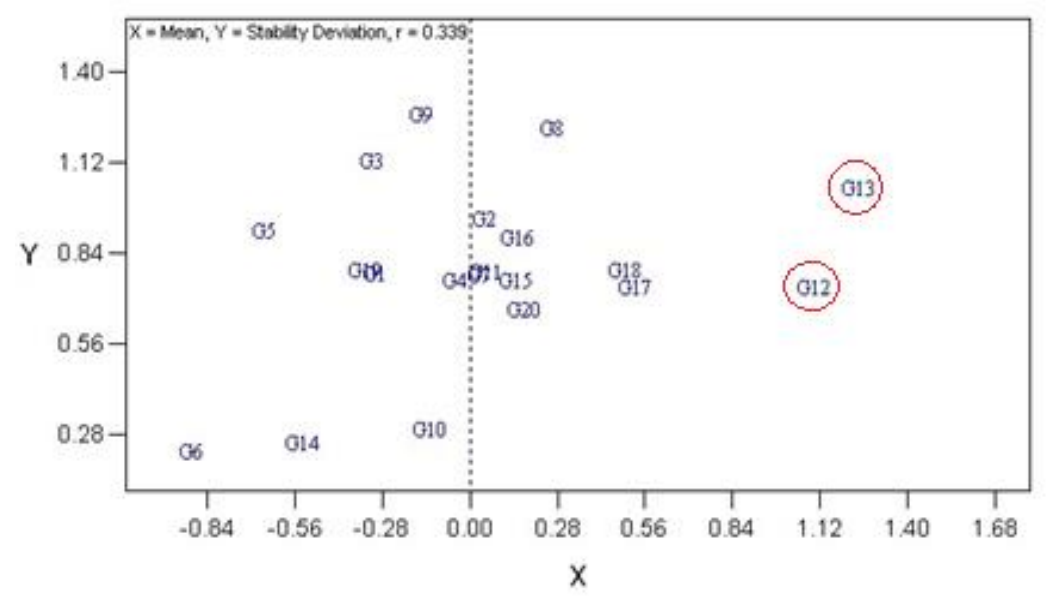

Figure 9. Shukla's Stability Index and Mean yield in chickpea genotypes

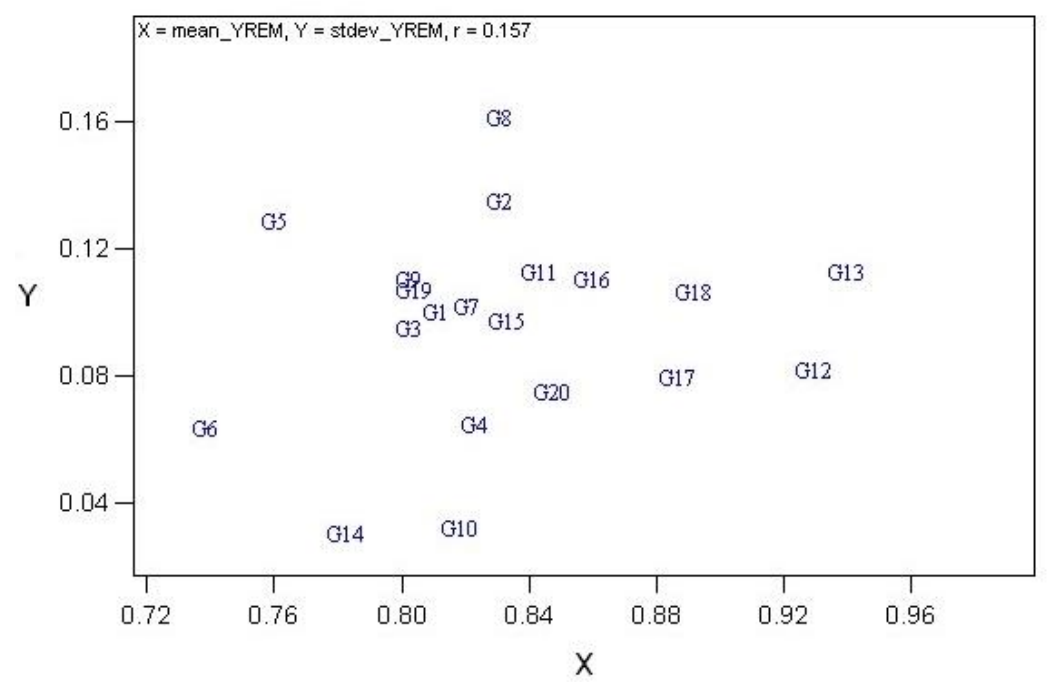

Figure 10. Mean yield of superiority index for each chickpea genotype in all test environments

Concurrent selection for yield and stability is one of the most important considerations in breeding plans (Yan and Kang, 2002). GGE biplot analysis with a user-friendly graphical interface can analyze different kinds of two-way data and provide a quick and complete understanding of the relationships between genotypes, environments, and their interactions. In this regard, the results of a study by Farshadfar (2011), investigating phenotypic stability evaluation in 17 chickpea genotypes in five research stations in Iran using the GGE biplot methodology, pointed up that the environment explained $86.44 \%$; the genotype $2.48 \%$; and the $\mathrm{G} \times \mathrm{E} 11.8 \%$ of the total variations of $\mathrm{G}+\mathrm{E}+\mathrm{GE}$ equation. The overall biplot analysis revealed three large environments from five research sites for chickpeas in Iran. Sabaghpour (2010) used GGE biplot in studying the stability of seed yield in 16 chickpea genotypes in autumn crop under rainfed conditions for three years. They also analyzed the two sites of Gachsaran and Gonbad separately and examined the interaction between year and location as well as genotype and year. 


\section{Conclusion}

One of the main subjects among plant breeders is to understand the concept of the relationship between crop yield and environment. Analysis of the $\mathrm{G} \times \mathrm{E}$ is one of the substantial issues in plant breeding, which is very important in the development and expansion of new cultivars. In this experiment, $\mathrm{G} \times \mathrm{E}$ of advanced chickpea genotypes in tropical and subtropical rainfed regions in Iran were investigated. The main effects of genotype and environment as well as the $\mathrm{G} \times \mathrm{E}$ were significant and the environment caused the most variations in seed yield. The highest mean seed yield of chickpea genotypes was observed in Khorramabad $\left(2353.557 \mathrm{~kg} \mathrm{ha}^{-1}\right)$ and the lowest was observed in Gachsaran (1029.065 $\left.\mathrm{kg} \mathrm{ha}^{-1}\right)$. GGE biplot analysis and which-won-where pattern of 20 genotypes showed that G13 was the most stable genotype for Khorramabad, Gonbad and Gachsaran, and G12 was the highest yielding and most stable and suitable genotype for Ilam. Based on the average environment coordinates, G13 was the highest yielding and most stable genotype in the average environment. Based on the biplot of comparison of all genotypes with the ideal genotype, G13 was identified as a stable and top-yielding genotype among all genotypes and environments. Based on the mean seed yield and Shukla's Stability Index, as well as the mean yield in relation with maximum or Superiority Index, G13 and G12 are superior and more stable than all other genotypes in the whole tropical regions in southern area of Iran; hence they are well recommended. Also, evaluation of the qualitative traits of the genotypes studied in this experiment can be recommended for future research.

Acknowledgements. The authors thank the Iranian Dryland Agricultural Research Institute for making available the plant materials, experimental locations and technical assistance.

\section{REFERENCES}

[1] Bartlett, M. S. (1937): Properties of sufficiency and statistical tests. - Proceedings of the Royal Society A 160: 268-282.

[2] Cravero, V., Espósito, M. A., Lopez-Anido, F., García, S. M., Cointry, E. (2010): Identification of an ideal test environment for asparagus evaluation by GGE-biplot analysis. - Australian Journal of Crop Science 4(4): 273-277.

[3] Dehghanpour, Z., Karimizadeh, R., Dehghani, H., Sabaghnia, N. (2007): Determination of adaptability and stability of seed yield in foreign earl maturity. - Iranian Journal of Agricultural Sciences 38: 249-257. (In Persian with English Abstract).

[4] Eskridge, K. (1996): Analysis of multiple environment trials using the probability of outperforming a check. - In: Kang, M. S., Gauch, H. (eds.) Genotype by environment interaction. CRC Press, NY, USA, pp. 273-307.

[5] FAO. (2012): Food and Agriculture Organization of the United Nations. - Rome, Italy.

[6] Farshadfar, E. (1998): Application of Biometrical Genetics in Plant Breeding. - Razi University. Kermansha, Iran.

[7] Farshadfar, E., Zali, H., Mohammadi, R. (2011): Evaluation of phenotypic stability in chickpea genotypes using GGEBiplot. - Annals Biology Research 2(6): 282-292.

[8] Farshadfar, E., Sabaghpour, S. H., Zali, H. (2012): Comparison of parametric and nonparametric stability statistics for selecting stable Chickpea (Cicer arietinum L.) genotypes under diverse environments. - Australian Journal of Crop Sciences 6(3): 514-524.

[9] Farshadfar, E., Rashidi, M., Jokar, M., Zali, H. (2013): GGE biplot analysis of genotype $\times$ environment interaction in chickpea genotypes. - Eur. Journal of Experimental Biology 3(1): 417-423. 
[10] Gabriel, K. R. (1971): The biplot graphic display of matrices with application to principal component analysis. - Biometrika 58: 453-467.

[11] Gan, Y. T., Siddique, K. H. M., MacLeod, W. J., Jayakunar, P. (2005): Management options of minimizing the damage by ascochyta blight (Ascochyta rabiei) in chickpea (Cicer arietinum L.). - Field Crops Research 97: 121-134.

[12] Gauch, H. G. Jr., Zobel, R. W. (1996): AMMI analysis of yield trials. - In: Kang, M. S., Gauch, H. G. Jr. (eds.) Genotype-by-environment interaction. CRC Press, Boca Raton, FL, pp. 85-122.

[13] Grubbs, F. E. (1969): Procedures for Detecting Outlying Observations in Samples. Technometrics 11: 1-21.

[14] Jabbari, H., Zeinalzadeh-Tabrizi, H., Enayati-Shariatpanahi, M. (2019): Response of germination and seedling traits in different canola genotypes to soil moisture conditions using GGEBiplot method. - Iranian Journal of Seed Science and Technology. Doi:10.22034/ijsst.2019.124388.1245. (In press).

[15] Kang, M. S. (1993): Simultaneous selection for yield and stability in crop performance trials: Consequences for growers. - Journal of Agronomy 85(3): 754-757.

[16] Kanouni, H., Taleei, A. R., Khalily, M. (2007): Stability analysis of seed yield and onehundred seeds weight in Desi type chickpea genotypes. - Seed and Plant Improvement Journal 23(3): 297-310. (In Persian).

[17] Kanouni, H., Farayedi, Y., Sabaghpour, S. H. (2016): Assessment of genotype $\times$ environment interaction effect on seed yield of chickpea (Cicer arietinum L.) lines under rainfed winter planting conditions. - Iranian Journal of Crop Sciences 18(1): 63-75. (In Persian).

[18] Karimizadeh, R., Mohammadi, M., Sabaghni, N., Mahmoodi, A. A., Roustami, B., Seyyedi, F., Akbari, F. (2013): GGE biplot analysis of yield stability in multi-environment trials of lentil genotypes under rainfed condition. - Notulae Scientia Biologicae 5(2): 256.

[19] Karimizadeh, R., Asghari, A., Chinipardaz, R., Sofalian, O., Ghaffari, A. (2016): Determining yield stability and model selection by AMMI method in rain-fed durum wheat genotypes. - Turkish Journal of Field Crops 21(2): 174-183.

[20] Karimizadeh, R., Asghari, A., Chinipardaz, R., Sofalian, O., Ghaffari, A., Shahbazi, K., Hosseinpour, T., Ghogog, H., Armion, M. (2019): Use of principal coordinate analysis for measuring GE interactions in rain-fed durum wheat genotypes. - Journal of Agriculture Sciences 25: 38-46.

[21] Kheybari, M., Saifzadeh, S., Shirani-Rad, A. H., Hadidi-Masouleh, E., Zakerin, H. R., Zeinalzadeh-Tabrizi, H. (2019): Determination of suitable planting date and stable genotype in cultivars and promising lines of rapeseed (Brassica napus L.) using GGE Biplot graphical analysis. - Applied Field Crops Research. (In press). Doi:10.22092/aj.2019.121709.1295.

[22] Levene, H. (1960): Robust testes for equality of variances. - In: Olkin, I. (ed.) Contributions to Probability and Statistics. Stanford Univ. Press, Palo Alto, CA, pp. 278292.

[23] Maqbool, M. A., Aslam, M., Ali, H., Mahmud Shah, T., Atta, B. M. (2015): GGE biplot analysis based selection of superior Chickpea (Cicer arietinum L.) inbred lines under variable water environments. - Pakistan Journal of Botany 47(5): 1901-1908.

[24] Mohammadi, R., Armion, M., Zadhasan, E., Ahmadi, M. M., Sadeghzadeh Ahari, D. (2012): Genotype $\times$ environment interaction for grain yield of rainfed durum wheat using the GGE biplot model. - Seed and Plant Improvement Journal 28(3): 503-518. (In Persian).

[25] Mohammadi, M., Hosseinpour, T., Armion, M., Khanzadeh, H., Ghojogh, H. (2016): Analysis of genotype, environment and genotype $\times$ environment interaction in bread wheat genotypes using GGE biplot. - Agriculture Communications 4(3): 1-8.

[26] Mostafavi, K., Mohammadi, A., Khodarahmi, M., Zabet, M., Zare, M. (2013): Yield response of commercial canola cultivars to different locations using graphical GGE biplot method. - Iranian Journal of Agronomy Plant Breeding 8(4): 133-143. (In Persian). 
[27] Navabi, A., Yang, R., Helm, J., Spaner, D. M. (2006): Can spring wheat-growing mega environments in the northern Great Plains be dissected for representative locations or nicheadapted genotypes. - Journal of Crop Sciences 46: 1107-1116.

[28] Omrani, S., Mohammad Naji, A., Esmaeilzadeh-Moghaddam, M. (2017): Yield stability analysis of promising bread wheat lines in southern warm and dry agroclimatic zone of Iran using GGE biplot model. - Journal of Crop Breeding 23(9): 157-165. (In Persian).

[29] Pourdad, S. S., Jamshidmoghadam, M. (2013): Study on genotype $\times$ environment interaction through GGE biplot for seed yield in spring rapeseed (Brassica napus L.) in rain-fed condition. - Journal of Crop Breeding 5(12): 1-14. (In Persian).

[30] Sabaghpour, S. H., Pezeshkpour, P., Sarparast, R., Saeid, A., Safikhani, M., Hashembeigi, A., Karami, E. (2010): study of grain yield stability in chickpea (Cicer arietinum L.) genotypes in autumn planting in dryland conditions. - Seed and Plant Improvement Journal 26: 173-191. (In Persian).

[31] Shapiro, S. S., Wilk, M. B. (1965): An Analysis of Variance Test for Normality (Complete Samples). - Biometrika 52: 591-611.

[32] Shiri, M. R., Bahrampour, T. (2015): Genotype $\times$ environment interaction analysis using GGE biplot in grain maize (Zea mays L.) hybrids under different irrigation conditions. Cereal Res 5(1): 83-94. (In Persian).

[33] Tabrizi, H. Z. (2012): Genotype by environment interaction and oil yield stability analysis of six sunflower cultivars in Khoy, Iran. - Advances in Environmental Biology 6: 227-231.

[34] Usefi, M., Dashti, H., Bihamta, M. R., Madah Hosseini, Sh. (2017): Analysis of genetic diversity in agronomic traits of chickpea (Cicer arietinum L.) genotypes using multivariate methods. - Iranian Journal of Field Crop Sciences 48: 567-578. (In Persian).

[35] Varshney, R. K., Song, C., Saxena, R. K., Azam, S., Yu, S., Sharpe, A. G. (2013): Draft genome sequence of chickpea (Cicer arietinum L.) provides a resource for trait improvement. - Nature Biotechnology 31: 240-246.

[36] Yan, W. (1999): A study on the methodology of cultivar evaluation based on yield trial data - with special reference to winter wheat in Ontario. - Ph.D Dissertation, University of Guelph, Guelph, Ontario, Canada.

[37] Yan, W., Hunt, L., Sheng, Q., Szlavnics, Z. (2000): Cultivar evaluation and megaenvironment investigation based on the GGE biplot. - Journal of Crop Sciences 40(3): 597605 .

[38] Yan, W. (2001): GGEbiplot-a Windows application for graphical analysis of multienvironment trial data and other types of two-way data. - Journal of Agronomy 93(5): 1111-1118.

[39] Yan, W., Kang, M. S. (2002): GGE biplot analysis: A graphical tool for breeders, geneticists, and agronomists. - CRC press. Boca, Raton, FL.

[40] Yan, W., Tinker, N. A. (2006): Biplot analysis of multi-environment trial data: Principles and applications. - Canadian Journal Plant Sciences 86: 623-645.

[41] Yan, W., Fregeau-Reid, J., Pageau, D., Martin, R., Mitchell-Fetch, J., Etienne, M., Rowsell, J., Scott, P., Price, M., De Haan, B., Cummiskey, A., Lajeunesse, J., Durand, J., Sparry, E. (2010): Identifying essential test locations for oat breeding in eastern Canada. - Crop Sciences 50: 504-515.

[42] Zali, H., Sabaghpour, S., Farshadfar, E., Pezeshkpour, P., Safikhani, M., Sarparast, R., Hashembeigi, A. (2007): Stability analysis of yield in chickpea genotypes by additive main effects and multiplicative interaction (AMMI). - Journal of Crop Production 11(42): 173180. (In Persian).

[43] Zali, H., Sofalian, O., Hasanloo, T., Asghari, A. (2016): AMMI and GGE biplot analysis of yield stability and drought tolerance in Brassica napus L. - Agricultural Communications 4(1): 1-8. 